University of Warwick institutional repository: http://go.warwick.ac.uk/wrap This paper is made available online in accordance with publisher policies. Please scroll down to view the document itself. Please refer to the repository record for this item and our policy information available from the repository home page for further information.

To see the final version of this paper please visit the publisher's website. Access to the published version may require a subscription.

Author(s): Helen M. GROGAN, Bruce A. T. ADIE, Richard H. GAZE, Michael P. CHALLEN and Peter R. MILLS

Article Title: Double-stranded RNA elements associated with the MVX disease of Agaricus bisporus

Year of publication: 2003

Link to published

version: http://dx.doi.org/10.1017/S0953756203007202

Publisher statement: None 


\title{
Double-stranded RNA elements associated with the MVX disease of Agaricus bisporus
}

\author{
Helen M. GROGAN, Bruce A. T. ADIE, Richard H. GAZE, Michael P. CHALLEN* and Peter R. MILLS \\ Horticulture Research International, Wellesbourne, Warwick CV35 9EF, UK. \\ E-mail:mike.challen@hri.ac.uk \\ Received 8 October 2002; accepted 9 January 2003.
}

\begin{abstract}
Double-stranded RNA (dsRNA) has been isolated from Agaricus bisporus fruit bodies exhibiting a wide range of disease symptoms. The symptoms which occurred singularly or in combination included; bare cropping areas on commercial beds (primordia disruption), crop delay, premature veil opening, off- or brown-coloured mushrooms, sporophore malformations and loss of crop yield. All symptoms were associated with loss of yield and/or product quality.

Collectively, these symptoms are described as mushroom virus X (MVX) disease. The dsRNA titre was much lower than that previously encountered with the La France viral disease of mushrooms and a modified cellulose CF11 protocol was used for their detection. A broad survey of cultivated mushrooms from the British industry identified dsRNA elements ranging between $640 \mathrm{bp}$ and $20.2 \mathrm{kbp}$; the majority have not previously been described in $A$. bisporus. 26 dsRNA elements were identified with a maximum of 17 , apparently non-encapsidated dsRNA elements, in any one sample. Three dsRNAs (16.2, 9.4 and $2.4 \mathrm{kbp})$ were routinely found in mushrooms asymptomatic for MVX. Previously, La France disease was effectively contained and controlled by minimising the on-farm production and spread of basidiospores. Our on-farm observations suggest that MVX could be spread by infected spores and/or mycelial fragments.
\end{abstract}

\section{INTRODUCTION}

Double-stranded RNA (dsRNA) elements have been observed in many different fungi. They can be either encapsidated within a protein coat or non-encapsidated where the dsRNAs reside as naked genetic elements (Buck 1986, 1998). The dsRNAs may be beneficial, detrimental or have no apparent effect on the host fungus. Encapsidated dsRNA mycoviruses were first characterised from diseased sporophores of the cultivated mushroom Agaricus bisporus (Hollings 1962). Several other viruses have also been identified in A. bisporus including various sized spherical and bacilliform particles (Dieleman-van Zaayen \& Temmink 1968, Hollings 1978, Revill, Davidson \& Wright 1994). The most severe of these viruses, associated with La France or dieback disease, comprises $35 \mathrm{~nm}$ particles and harbours nine dsRNA molecules (Marino et al. 1976, Harmsen, van Griensven \& Wessels 1989, Goodin, Schlagnhaufer \& Romaine 1992). The La France virus caused extensive crop losses to the British mushroom industry during the 1960-70s. La France disease was effectively contained and controlled by adopting viral hygiene practices that minimised the on-farm production and

\footnotetext{
* Corresponding author.
}

spread of basidiospores. The $35 \mathrm{~nm}$ dsRNA isometric virus has been the subject of extensive epidemiological studies (Schisler, Sinden \& Sigel 1963, 1967, van Zaayen 1979, Romaine, Ulhrich \& Schlagnhaufer 1993) and molecular characterisation (Harmsen et al. 1989, 1991, van der Lende, Harmsen \& Wessels 1994, Goodin et al. 1997). Occurrence of La France disease is now extremely rare in British mushroom crops.

In recent years, a novel disease has become prevalent in the British mushroom industry. During autumn 1996, a mushroom farm reported cropping problems for which no satisfactory explanation could be found. The symptom consisted of localised areas or patches of mushroom bed where no primordia (pins) developed and where no obvious cause could be identified (Gaze 1999). From 1996 to 2000, the number of affected farms and the range of symptoms increased. A few symptoms were consistent with La France but commercial tests for the $35 \mathrm{~nm}$ virus proved negative. Recently, the disease was associated with the presence of novel dsRNA elements (Gaze et al. 2000). However, the dsRNAs did not resemble those previously described in A. bisporus and were substantially different from those characterised for La France disease.

The disease was termed 'virus $\mathrm{X}$ ' as characterisation of the dsRNAs was lacking (Gaze et al. 2000). 
This paper details the variety of symptoms associated with the mushroom virus X (MVX) disease, describes the extraction and characterisation of novel dsRNA elements from $A$. bisporus fruit bodies, and indicates that utilisation of appropriate viral hygiene measures on-farm can reduce the impact of MVX.

\section{MATERIALS AND METHODS}

\section{MVX symptoms and mushroom samples}

Mushroom farms experiencing MVX were visited in order to obtain pictures and details of disease symptoms. In Oct. 2000-May 2001, 320 mushroom samples (both 'healthy' and diseased) were received from farms and analysed for the presence of dsRNAs. Prior to storage at $-20^{\circ} \mathrm{C}, 150 \mathrm{~g}$ samples of fruit bodies were broken into small pieces. To increase the available biomass during subsequent dsRNA extractions, fruit body tissues were lyophilised for 3-4 d.

\section{Extraction and electrophoresis of dsRNA}

RNAs were isolated from freeze-dried fruit bodies using a modification of earlier protocols (Wach, Sriskantha \& Romaine 1987, Romaine \& Schlagnhaufer 1993, Goodin et al. 1997). All buffers and reagents were prepared using dimethylpyrocarbonate (DMPC) treated water (van Miltenburg et al. 1995). A $10 \mathrm{~g}$ dry weight sample was ground to a fine powder under liquid nitrogen using a sterile mortar and pestle. The powder was added to $60 \mathrm{ml}$ of $2 \times$ STE buffer (Wach et al. 1987) and $1 \% \mathrm{w} / \mathrm{v}$ SDS in a centrifuge tube and mixed with a sterile glass rod to form an homogeneous paste. The mixture was gently extracted using 0.5 vols each of saturated phenol $\mathrm{pH} 4.5$ and chloroform/ isoamyl alcohol (24:1) and centrifuged at $2500 \boldsymbol{g}$ for $20 \mathrm{~min}$. Using a pipette, the aqueous phase was transferred to a clean centrifuge tube and then centrifuged at $8000 \mathrm{~g}$ for $10 \mathrm{~min}$ to minimise contaminating phenol and/or particulate matter. Absolute ethanol was added to the purified aqueous phase to a final concentration $15 \% \mathrm{v} / \mathrm{v}$ and dsRNAs were recovered by the addition of $1.5 \mathrm{~g}$ fibrous cellulose powder CF11 (The Labsales Co., Cambridge). The preparation was held on ice for 30 min with mixing every $10 \mathrm{~min}$ and then centrifuged at $8000 \mathrm{~g}$ for $10 \mathrm{~min}$. The CF11-dsRNA complex was resuspended in $15 \mathrm{ml}$ STE buffer with $15 \% \mathrm{v} / \mathrm{v}$ ethanol (Wach et al. 1987) and centrifuged at $8000 \mathrm{~g}$ for $10 \mathrm{~min}$; these washes were repeated seven times to remove DNA and single-stranded RNA. The dsRNAs were solubilised by the addition of $10 \mathrm{ml}$ STE buffer (without ethanol) and centrifugation at $8000 \mathrm{~g}$ for $10 \mathrm{~min}$. To eliminate the CF11, the supernatant was filtered through glass wool equilibrated with STE. Nucleic acids were precipitated overnight at $-20^{\circ}$ using 2 vols ethanol, $0.1 \mathrm{vol} 3 \mathrm{~m}$ pH 5.2 sodium acetate and centrifugation at $8000 \mathrm{~g}$ for $10 \mathrm{~min}$. The pellet was washed with $70 \% \mathrm{v} / \mathrm{v}$ ethanol and resuspended in
$500 \mu 1$ water, precipitated again using ethanol and sodium acetate for $1-2 \mathrm{~h}$ at $-70^{\circ}$ and centrifugation at $11000 \mathrm{~g}$ for $15 \mathrm{~min}$. The pellet was washed in $70 \% \mathrm{v} / \mathrm{v}$ ethanol, air-dried for 20 min and finally resuspended in $32 \mu 1$ water.

Where appropriate dsRNA preparations were treated with RQ1 RNase-free DNase (Promega Corporation, Madison, WI) and S1 nuclease (Promega) according to the manufacturer's recommendations. Following nuclease treatments, dsRNA was purified using QIAquick PCR spin columns (Qiagen, Crawley) and eluted in $30 \mu \mathrm{l}$ water. The double-stranded integrity of RNA products was confirmed using RNase nuclease treatments at differential salt concentrations (van der Lende et al. 1994).

Samples were analysed electrophoretically using $0.7 \% \mathrm{w} / \mathrm{v}$ agarose, ethidium bromide and TAE buffer (Sambrook, Fritsch \& Maniatis 1989). Gel images were captured using Grabber software v. 2.00 (Phoretix International, Newcastle-upon-Tyne). Molecular weights were determined from migration rates using Phoretix 1D Gel Analysis package v. 4.01 (Phoretix International) and various markers: marker III from Roche Diagnostics (Lewes), and a 100 bp ladder (Invitrogen, Paisley). The higher molecular weight dsRNA bands were sized using $0.4 \% \mathrm{w} / \mathrm{v}$ agarose and a high molecular weight marker (Invitrogen).

\section{On-farm observations}

Regular contact with a number of farms since the onset of MVX disease enabled detailed case histories to be established. This was done in conjunction with regular analysis of fruit body samples for the presence of MVX dsRNAs. Some farms have succeeded in becoming relatively free of MVX, while others have continued to experience symptoms. Three contrasting sites were chosen to illustrate as many facets of disease epidemiology as possible. Because MVX disease is associated with mushroom production, there is a need to describe some industry practices in this manuscript. Explanations of mushroom production terminology can be found in Fletcher, White \& Gaze (1989) and van Griensven (1988).

\section{RESULTS}

\section{Symptoms of MVX disease}

Mushroom farms suffering from MVX reported a wide variety of symptoms, which could be grouped into five major categories as follows: pinning disruption and associated crop delay, premature opening, off- or brown-coloured mushrooms, malformations, and loss of yield (Fig. 1a-h). Only off- or brown-coloured mushrooms were specific to MVX, the remaining symptoms can occur as a result of several other disorders, including La France disease. Consequently, positive confirmation of novel dsRNAs was needed before symptoms could be ascribed to MVX disease. 


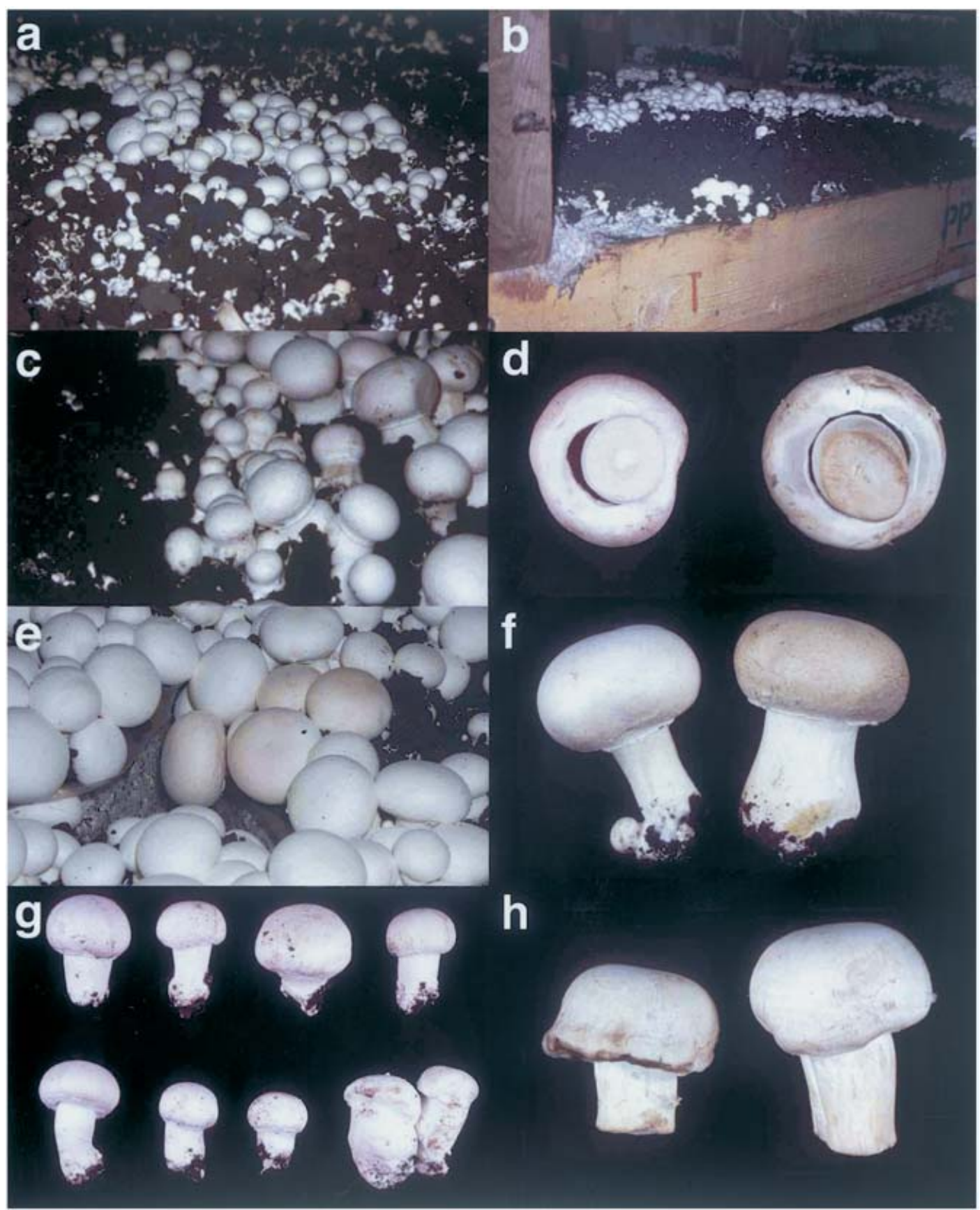

Fig. 1. MVX symptomology in Agaricus bisporus: (a) area of mushroom bed showing pin suppression around a group of normal mushrooms; in MVX-free production, beds would be uniformly covered with mushrooms; (b) bare area in mushroom tray with no pins developing; (c) gradation in pin development from no pins on left to fully developed mushrooms on right; (d) premature opening of mushrooms; (e) off coloured 'brown' mushrooms from a white strain; (f) 'brown' mushroom with thickened stipe on right, compared with normal white mushroom; and (g-h) malformed and misshapen fruit bodies.

\section{Pinning disruption and crop delay}

Mushroom pins formed normally on the beds, but their subsequent development and growth was delayed by one to several days, resulting in crop delay. Either the whole or a small area of bed could be affected (Fig. 1a). In other cases, large or small areas of bare, nonproductive bed or 'patches' occurred where pins failed to develop (Fig. 1b). This easily recognisable symptom led to the use of the descriptor 'patch' disease. These non-productive areas differed in size and shape. They ranged between being circular, forming swirls down the length of a bed, to covering large irregular or geometrical swathes of the bed. Frequently, non-productive areas would grade into late developing pins and then into apparently healthy mushrooms (Fig. 1c). Mushrooms sampled from asymptomatic beds/trays within an affected house usually contained the same dsRNAs as those from the affected location. In many cases, mushrooms eventually developed in the bare areas, 


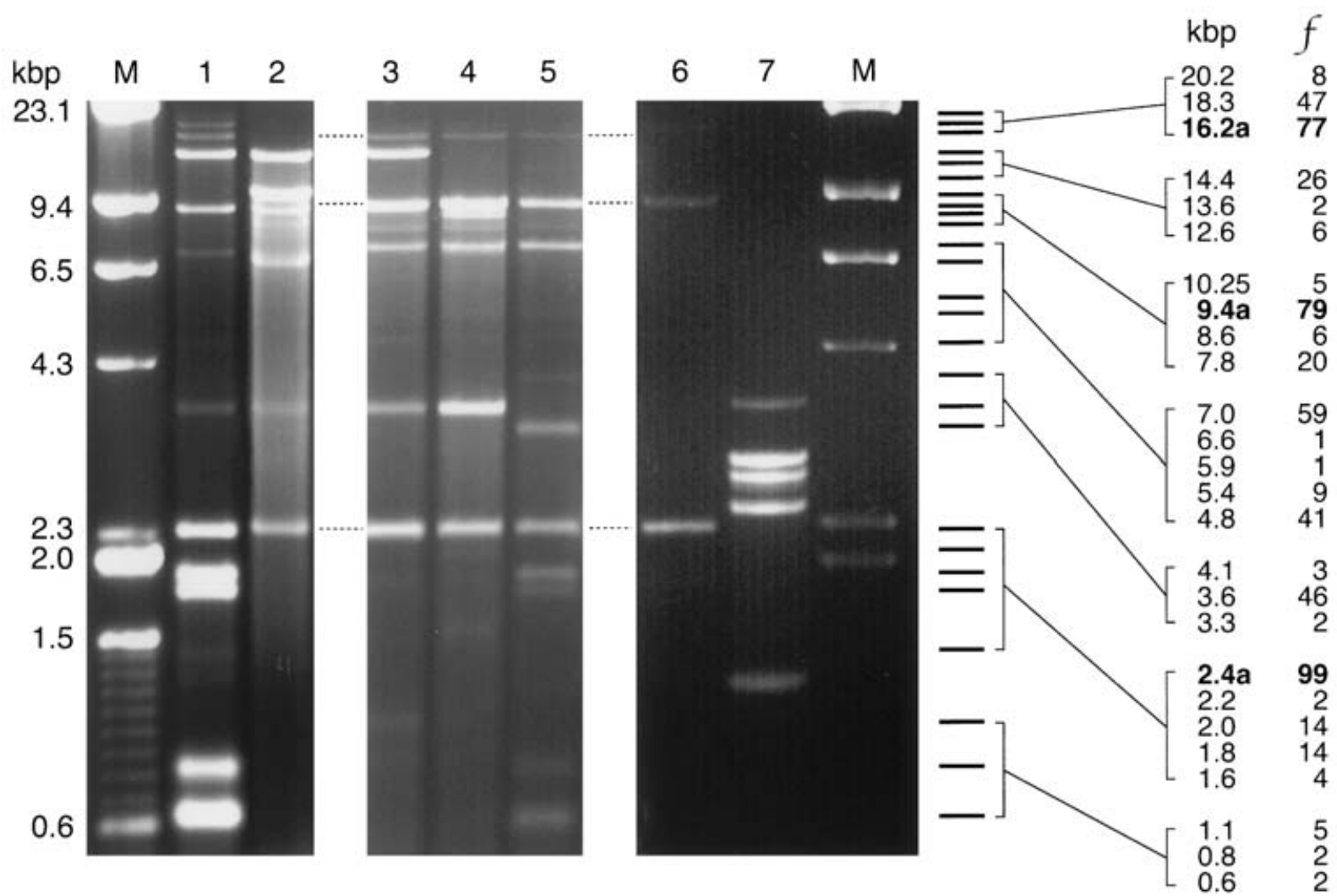

Fig. 2. Agarose electrophoresis of dsRNAs from Agaricus bisporus. Lanes 1-5, example dsRNA extractions from different MVX samples: lane 6, dsRNA extraction from sporophores asymptomatic for MVX; lane 7, dsRNA extraction from sporophores infected with La France virus; lane M, molecular weight markers. Schematic indicates relative size of 26 dsRNA elements observed during this study. Molecular weight $(\mathrm{kbp})$ and frequency $(f)$ data are indicated for each dsRNA element. Location of asymptomatic dsRNAs are indicated by broken lines, and highlighted in the schematic with the suffix 'a' and emboldened text.

but were out of synchronisation with the rest of the crop.

\section{Premature opening}

Mushrooms growing on the beds would appear normal. Once picked and turned over however, it became apparent that the veils had opened prematurely, resulting in a loss of quality and downgrading of the commercial product (Fig. 1d). In the worst cases, fruit body veils were completely lacking. This symptom often appeared only in the second flush.

\section{Off- or brown-coloured mushrooms}

On some sites, the only symptom to be observed was the presence of off-coloured or brown mushrooms throughout a crop spawned with a white strain (Fig. 1e-f). The brown symptom could range from only a few mushrooms on a bed, to $c a 40 \%$ of a total crop. MVX dsRNAs were also found in apparently 'normal' mushrooms from within the same crop; some of these mushrooms would discolour rapidly in storage, leading to the downgrading or rejection of product. The brown-coloured symptom is the only one unique to MVX, but it does not occur in all diseased crops.

\section{Sporophore malformations and loss of yield}

In cases where symptoms and yield losses were very severe, mushrooms were often malformed and looked similar to La France disease (Fig. 1g-h). Where symptoms were most severe, yield losses were as high as $50-80 \%$.

\section{DsR A profiles}

Mushrooms exhibiting the different symptoms of MVX invariably harboured a variety of dsRNA elements. Using agarose electrophoresis, up to 26 different dsRNA bands were detectable (Fig. 2), ranging between $640 \mathrm{bp}$ and $20.2 \mathrm{kbp}$. Three dsRNAs ( ${ }^{\mathrm{MVX}} 16.2^{\mathrm{a}}$, $\operatorname{MVX}_{9.4^{\mathrm{a}}}$ and $\mathrm{MVX}_{2.4^{\mathrm{a}}}$ ) were routinely found in mushroom samples asymptomatic for MVX and occurred at sites that have never exhibited the disease. The remaining 23 MVX bands were always associated with symptoms, or sites with a history of symptoms. Four low molecular weight dsRNAs $\left(\mathrm{MVX}_{2.0},{ }^{\mathrm{MVX}}{ }_{1.8}\right.$, $\operatorname{MVX}_{0.8}, \operatorname{MVX}_{0.6}$ ) were regularly associated with the occurrence of the brown symptom. With this exception, there was no obvious correlation between the presence of different dsRNAs and the various symptoms observed. 
The maximum number of dsRNAs to occur in any one sample was 17 . Individual profiles varied considerably between samples, although samples taken from a single source at different times usually gave similar results (data not presented). Some dsRNA elements occurred more often than others, and the frequency of each dsRNA is summarised in Fig. 2. From the 320 samples tested in this study, $13 \%$ contained only asymptomatic dsRNAs and were from sites classed as either negative for MVX or recovering from the disease. A further $29 \%$ with up to two extra dsRNAs were from sites thought to be recovering, while $58 \%$ of samples with three or more extra dsRNAs came from sites with significant MVX problems. The asymptomatic dsRNA elements occurred most frequently (Fig. 2). Only six other dsRNAs occurred in more than $20 \%$ of samples. The remaining elements occurred with frequencies ranging between 0.6 and $16 \%$.

\section{On-farm observations}

\section{Site 1}

A large scale facility producing non-inoculated (bulk phase II) and fully-colonised (bulk phase III) composts in bulk tunnels for distribution to mushroom farms. The phase II compost was either: (1) inoculated with Agaricus bisporus mycelium (spawned phase II) in relatively unprotected conditions prior to 'blocking' and dispatch to mushroom farms; or (2) spawned in enclosed conditions then filled into phase III tunnels for incubation. The spawn-run phase III compost was emptied from the opposite end of the tunnel, physically isolated from the spawning operation. No mushrooms were grown on site or in the vicinity. The most likely source of dsRNA-containing material was the $A$. bisporus mycelium from the phase III compost. During 1999, MVX symptoms were apparent on farms receiving compost from this facility. They were, however, more frequent and severe with the phase III compost. Samples of both phase II and III composts were sampled and grown in isolation on an uninfected site (HRI, Wellesbourne). Mushrooms from the phase II compost contained a total of eight dsRNA elements ( ${ }^{\mathrm{MVX}} 18.3$, $\left.16.2^{\mathrm{a}}, 9.4^{\mathrm{a}}, 8.6,7.8,7.0,3.6,2.4^{\mathrm{a}}\right)$, those from the phase III compost contained nine dsRNAs ( ${ }^{M V X} 18.3,16.2^{\mathrm{a}}$, $\left.14.4,9.4^{\mathrm{a}}, 8.6,7.8,7.0,3.6,2.4^{\mathrm{a}}\right)$ and the high intensity of $\mathrm{MVX}_{14.4}$ was striking in agarose gels. We hypothesised that there was no effective physical virus barrier between the phase III emptying hall (a source of mycelium harbouring MVX) and the phase II spawning areas. This would enable 'infected' mycelial fragments to be continually introduced into the freshly spawned compost. During 2000, virus hygiene programmes were reviewed at Site 1 and modified to prevent the contamination of all phase II compost at spawning. Throughout the next year, MVX dsRNAs, as well as symptoms, continued to be detected in crops for a period of time but gradually reduced in number and intensity. In 2002, analyses of mushrooms from Site 1 composts indicated that only asymptomatic dsRNAs were present at detectable levels. Crops that gave normal yields had no symptoms.

\section{Site 2}

This site produced both compost and mushrooms on an isolated, self-sufficient, medium to large scale farm. A 'single zone' system was employed in which phase I compost was filled onto shelves in purpose built rooms. All subsequent processes (pasteurisation, spawning, spawn-running and cropping) took place in situ. This site had a previous history of La France disease. In 1998 non-productive areas of mushroom bed reduced yields to $c a 40 \%$ of normal. Analysis of mushrooms confirmed the presence of nine dsRNA elements $\left({ }^{M V X} 16.2^{\mathrm{a}}, 12.6,9.4^{\mathrm{a}}, 8.6,7.0,5.9,4.1,3.6,2.4^{\mathrm{a}}\right)$. It was hypothesised that mushroom spores, were continually passing from old to new crops, infecting both phase II compost and spawn-running crops. Air filtration to all rooms was identified as inadequate and considerable volumes of unfiltered air were entering rooms through poor door seals. The pasteurisation regime for raw phase I compost was also ineffective, allowing mushroom spores to survive. Effective air filtration was installed, the pasteurisation regime was improved, and all door-seals were replaced. A dramatic increase in the $\mathrm{CO}_{2}$ levels during spawn-running, confirmed that unfiltered fresh air had been entering the rooms through faulty door seals. Cropping returned to normal within a few months of the modifications and analysis of mushrooms in March 2000 indicated that dsRNAs

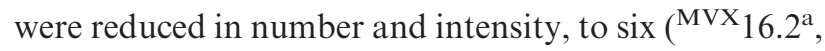
$\left.10.2,9.4^{\mathrm{a}}, 7.0,3.6,2.4^{\mathrm{a}}\right)$. By Nov. 2000, these were reduced further to four ( $\left.{ }^{\mathrm{MVX}} 16.2^{\mathrm{a}}, 9.4^{\mathrm{a}}, 2.4^{\mathrm{a}}, 1.1\right)$.

\section{Site 3}

A compact farm producing mushrooms on a large scale. Raw phase I compost was delivered to the farm and pasteurised in on-site tunnels to produce bulk phase II compost. Spawned compost was filled into phase III tunnels adjacent to the phase II pasteurising tunnels. The spawn-run (bulk phase III) compost was then emptied into the same hall used for spawning, transported by trailer to the nearby cropping units and filled onto shelves by conveyors. When all spawn-run compost was emptied from the tunnels there followed a thorough cleaning and disinfection regime to remove potential virus-containing mushroom mycelium, in preparation for another spawning operation the following week. Site 3 experienced a serious occurrence of La France when it began production, but in later years it had been free of viral problems. During March 2001 virtually all known MVX symptoms were observed on Site 3 and 15 dsRNA elements ( ${ }^{M^{2} x_{20}}$.1, 18.3, 16.2 ${ }^{\mathrm{a}}$, $\left.14.4,9.4^{\mathrm{a}}, 8.6,7.0,5.4,4.8,3.6,2.4^{\mathrm{a}}, 2.0,1.8,0.8,0.6\right)$ were observed in mushroom samples. During a farm 
hygiene audit, multiple opportunities for spore and mycelial contamination were identified. The design of the site, with a common hall and equipment for spawning and emptying was considered a major weakness. Revisions of hygiene procedures did not result in a cessation of symptoms or a reduction in the number of dsRNAs elements. In Jan. 2002, mushroom samples from the farm harboured 16 dsRNA elements $\left({ }^{M V X} 18.3,16.2^{\mathrm{a}}, 9.4^{\mathrm{a}}, 8.6,7.8,7.0,4.8,3.6,3.3 .2 .4^{\mathrm{a}}\right.$, $2.0,1.8,1.6,1.1,0.8,0.6)$. In July 2002, Site 3 ceased production of bulk phase III and began buying in spawned phase II compost to fill directly onto shelves. Crops returned to normal and mushrooms contained only asymptomatic dsRNAs ( $\left.{ }^{\mathrm{MVX}} 16.2^{\mathrm{a}}, 2.4^{\mathrm{a}}\right)$.

\section{DISCUSSION}

MVX disease of the commercial mushroom Agaricus bisporus encompasses a diverse range of symptoms, which can occur together or individually on a given site. This relatively new disease (Gaze 1999) has had a devastating effect on the British mushroom industry. More recently, mushrooms showing the browning symptom have been observed elsewhere in Europe (Anton Sonnenberg, pers. comm.). Four medium to large British farms have closed as a consequence of MVX. These farms accounted for about $10 \%$ of total British mushroom production. During this time, 1999-2000, British mushroom production fell by $14 \%$ (14000 tonnes; DEFRA 2001).

To detect the MVX dsRNA elements, a relatively large quantity of material was used and this represents a divergence from the procedures used to detect the La France dsRNAs, which are typically present in higher titre. Early attempts to isolate dsRNA from putative MVX samples using standardised protocols (Wach et al. 1987, Romaine \& Schlagnhaufer 1993) indicated that any such nucleic acids were present in very low titre (Peter Romaine, pers. comm.). During this study, 26 dsRNA elements were detected in MVX fruit body samples. The number and size of dsRNAs, and the variation in their profiles suggests that MVX may comprise a complex of more than one virus. Three dsRNAs ( ${ }^{M V X} 16.2^{\mathrm{a}},{ }^{\mathrm{MVX}} 9.4^{\mathrm{a}}$ and ${ }^{\mathrm{MVX}} 2.4^{\mathrm{a}}$ ) were regularly observed in mushrooms asymptomatic for MVX. The remaining 23 dsRNAs were present in mushroom samples from sites with MVX symptoms, or a history of symptoms. Unlike La France, where nine major dsRNAs consistently correlate with the disease, there was no consistent banding pattern associated with MVX disease. Some dsRNA elements occurred more frequently than others; four elements ( ${ }^{\mathrm{MVX}} 18.3,7.0$, $4.8,3.6)$ appeared in $41-59 \%$ of samples while a further five ( $\left.{ }^{M V X} 14.4,8.6,7.8,2.0,1.8\right)$ occurred in $10-26 \%$ of samples. The remaining dsRNAs occurred infrequently.

The range of MVX symptoms encountered across British sites has varied. Some sites had very specific symptoms, for example only premature opening, or only pin suppression and bare areas, while other sites displayed a range of symptoms. Other than a tentative association of four dsRNA elements ( $\mathrm{MVX}_{2.0},{ }^{\mathrm{MVX}}{ }_{1.8}$, $\operatorname{MVX}_{0.8},{ }^{M V X}(0.6)$ with sporophore browning, clear relationships between individual dsRNAs and specific symptoms have not yet been defined.

In mushrooms infected with La France, nine major dsRNAs have been characterised (L1-3.6 kbp, L2-3.0 kbp, L3-2.8 kbp, L4-2.7 kbp, L5-2.5 kbp, M1-1.6 kbp, M2-1.35 kbp, S1-0.86 kbp \& S2-0.78 kbp; van der Lende et al. 1994) but in general, these span a smaller range than those of MVX (0.64-20.2 kbp). Another dsRNA that often appears in La France samples (L6-2.35 kbp; van der Lende et al. 1994) is also found in healthy mushrooms and may be equivalent to the $\mathrm{MVX}_{2.4^{\mathrm{a}}}$. Three asymptomatic dsRNA elements, sized $2.4,5.2$ and $>13 \mathrm{kbp}$, were previously found to be associated with membrane vesicles (Romaine \& Schlagnhaufer 1989, Romaine, Schlagnhaufer \& Goodin 1994). Estimating the size of larger dsRNAs is prone to considerable error and it's possible that MVX $16.2^{\mathrm{a}}$ corresponds to the $>13.1 \mathrm{kbp}$. It seems unlikely however, that ${ }^{\mathrm{MVX}} 9.4^{\mathrm{a}}$ relates to these previous descriptions.

With La France virus it has not been possible to confirm Koch's postulates. Similarly with MVX, in the absence of Koch's postulates, it is not possible to prove that the dsRNA elements described here are the cause of the MVX disease symptoms. With La France, experiments have demonstrated transmission of the disease via anastomosis between infected and healthy strains (Gandy \& Hollings 1962, Hollings 1962) and it has been shown that infected basidiospores can transfer the disease (Schisler, Sinden \& Sigel 1967). It appears that MVX can also be transmitted between crops via infected basidiospores. We have previously observed that multispore axenic cultures prepared from MVX diseased sporophores, and subsequent crops produced from those multispore cultures can maintain the dsRNA elements (Gaze et al. 2000). Our recent onfarm observations and epidemiological experiments suggest that infected spores and/or mycelial fragments can spread MVX. Implementing on-farm hygiene measures to reduce or eliminate the movement of spores and/or mycelial fragments, can effectively reduce the incidence of MVX, as determined by numbers and intensity of symptoms and dsRNA elements. On one farm (Site 3) with inherent design faults, elimination of contaminating mycelial fragments proved intractable and MVX persisted until bulk phase III production was stopped.

There is other evidence for higher molecular weight dsRNAs in A. bisporus (e.g. Romaine et al. 1994). Overloading of agarose gels with La France dsRNAs can reveal the 'minor' dsRNA elements; XL1-LX4 of about $15 \mathrm{~kb}, \mathrm{~L} 0-6.5 \mathrm{~kb}, \mathrm{~L} 7-2.0 \mathrm{~kb}, \mathrm{~L} 8-1.9 \mathrm{~kb}$ and S3$0.27 \mathrm{~kb}$ (Harmsen et al. 1989). In addition, extractions from $A$. bisporus mycelial cultures revealed dsRNA 
ranging between 8.8 and $15 \mathrm{~kb}$ (Morten \& Hicks 1992); in some cases these bands were present in healthy cultures. A few of the MVX dsRNAs are of similar size to those of La France and it remains to be determined whether such bands are dsRNA homologs. However, immediate comparisons are confounded by limited sequence data for La France dsRNAs (M2, M1 \& L3; Harmsen et al. 1991) and the disparity in reported sizes of such molecules (see above; Harmsen 1990).

DsRNA elements have been observed in other edible species; in Flammulina velutipes two dsRNAs of 1.9 and $1.8 \mathrm{kbp}$ and the presence of $50 \mathrm{~nm}$ particles were implicated in the spontaneous browning of sporophores (Magae \& Hayashi 1999). The occurrence of dsRNA elements in other fungi is well documented and their presence is not always detrimental to the fungus (Lemke \& Nash 1974). There are, however, several examples of hypovirulence associated with dsRNA in fungal plant pathogens (Day et al. 1977, Brasier 1983). Not all dsRNA mycoviruses are encapsidated, for example, the Cryphonectria parasitica hypovirulence dsRNAs occur within membrane vesicles (Hansen et al. 1985). Hitherto, transmission electron microscopy of MVX samples, has not revealed viral particles specifically associated with the disease (Carol Everard \& Colin Clay, unpubl.), which suggests the dsRNAs are non-encapsidated.

Mycoviral genomes can comprise multiple dsRNA segments (Buck 1986). Alternatively, multiple dsRNA molecules can result from subgenomic or defective interfering particles (Tartaglia et al. 1986, Hiremath et al. 1986). Indeed, the La France S3 dsRNA is an internally deleted variant of the M2 dsRNA (Harmsen et al. 1991). Our current research aims to gain a better understanding of the epidemiology of MVX to assist disease control strategies. We are cloning the dsRNA elements to determine relationships between them and to reveal the type of virus(es) present. MVX sequence data will be used in the development of a PCR based diagnostic for the mushroom industry.

\section{ACKNOWLEDGEMENTS}

The authors are grateful to Peter Romaine (Penn State University) who first revealed the presence of dsRNA in MVX disease, and to Leo Calvo-Bado for his role in modifying the extraction protocol. We also thank James Mulcahy for dsRNA extractions from industry samples. The MVX research was funded by grants to HRI from DEFRA and the Horticultural Development Council.

\section{REFERENCES}

Brasier, C. M. (1983) A cytoplasmically transmitted disease of Ceratocystis ulmi. Nature 305: 220-223.

Buck, K. W. (1986) Fungal virology-an overview. In Fungal Virology (K. W. Buck, ed.): 1-84. CRC Press, Boca Raton.

Buck, K.W. (1998) Molecular variability of viruses of fungi. In Molecular Variability of Fungal Pathogens (P. D. Bridge, Y. Couteaudier \& J. Clarkson, eds): 53-72. CAB International, Wallingford.
Day, P. R., Dodds, J. A., Elliston, J. E., Jaynes, R. A. \& Ananogstakis, S. L. (1977) Double-stranded RNA in Endothia parasitica. Phytopathology 67: 1393-1396.

DEFRA (2001) Basic Horticultural Statistics for the United Kingdom. Calendar and crop years 1990/91-2000/01. DEFRA Publications, London.

Dieleman-van Zaayen, A. \& Temmink, J. H. M. (1968) A virus disease of cultivated mushrooms in The Netherlands. Netherlands Journal of Plant Pathology 74: 48-51.

Fletcher, J. T., White, P. F. \& Gaze, R. H. (1989) Mushrooms: pest and disease control. 2nd edn. Intercept, Andover.

Gandy, D. G. \& Hollings, M. (1962) Die-back of mushrooms: a disease associated with a virus. Report of the Glasshouse Crops Research Institute 1961: 103-108.

Gaze, R. H. (1999) Virus in disguise? Mushroom Journal 590: 17-19.

Gaze, R. H., Calvo-Bado, L., Challen, M. P., Adie, B. \& Romaine, C. P. (2000) A new virus disease of Agaricus bisporus? Mushroom Science 15: 701-705.

Goodin, M. M., Schlagnhaufer, B. \& Romaine, C. P. (1992) Encapsidation of the La France disease-specific double-stranded RNAs in 36-nm isometric virus like particles. Phytopathology 82: 285-290.

Goodin, M. M., Schlagnhaufer, B., Weir, T. \& Romaine, C. P. (1997) Characterization of an RNA-dependent RNA polymerase activity associated with La France isometric virus. Journal of Virology 71: 2264-2269.

Hansen, D. R., van Alfen, N. K., Gillies, K. \& Powell, W. A. (1985) Naked dsRNA associated with hypovirulence of Endothia parasitica is packaged in fungal vesicles. Journal of General Virology 66: 2605-2614.

Harmsen, M. C. (1990) La France disease of the cultivated mushroom (Agaricus bisporus). PhD thesis, Rijksuniversitet Groningen, Wageningen.

Harmsen, M. C., Tolner, B., Kram, A., Go, S. J., de Haan, A. \& Wessels, J. G. H. (1991) Sequences of three dsRNAs associated with La France disease of the cultivated mushroom (Agaricus bisporus). Current Genetics 20: 137-144.

Harmsen, M. C., van Griensven, L. J. L. D. \& Wessels, J. G. H. (1989) Molecular analysis of Agaricus bisporus double-stranded RNA. Journal of General Virology 70: 1613-1616.

Hiremath, S., L'Hostis, B., Ghabrial, S. A. \& Rhoads, R. E. (1986) Terminal structure of hypovirulence associated dsRNAs in chestnut blight fungus Endothia parasitica. Nucleic Acids Research 14: 9877-9896.

Hollings, M. (1962) Viruses associated with a die-back disease of the cultivated mushroom. Nature 196: 962-965.

Hollings, M. (1978) Mycoviruses: viruses that infect fungi. Advances in Virus Research 22: 1-53.

Lemke, P. A. \& Nash, C. H. (1974) Fungal viruses. Bacteriological Reviews 38: 29-56.

Magae, Y. \& Hayashi, N. (1999) Double-stranded RNA and viruslike particles in the edible basidiomycete Flammulina velutipes (Enokitake). FEMS Microbiology Letters 180: 331-335.

Marino, R., Saksena, K. N., Schuler, M., Mayfield, J. E. \& Lemke, P. A. (1976) Double-stranded ribonucleic acid in Agaricus bisporus. Applied and Environmental Microbiology 31: 432-438.

Morten, K. J. \& Hicks, R. G. T. (1992) Changes in double-stranded RNA profiles in Agaricus bisporus during subculture. FEMS Microbiology Letters 91: 159-164.

Revill, P. A., Davidson, A. D. \& Wright, P. J. (1994) The nucleotide sequence and genome organisation of Mushroom Bacilliform virus: a single stranded RNA virus of Agaricus bisporus (Lange) Imbach. Virology 202: 904-911.

Romaine, P. C. \& Schlagnhaufer, B. (1989) Prevalence of doublestranded RNAs in healthy and La France disease-affected basidiocarps of Agaricus bisporus. Mycologia 81: 822-825.

Romaine, C. P. \& Schlagnhaufer, B. (1993) 'DsRNA Quick-Prep': an abbreviated method for the clinical diagnosis of La France disease. Cultivated Mushroom Research (CMR) Newsletter 1: 7-10. 
Romaine, C. P., Schlagnhaufer, B. \& Goodin, M. M. (1994) Vesicleassociated double-stranded ribonucleic acid genetic elements in Agaricus bisporus. Current Genetics 25: 128-134.

Romaine, C. P., Ulhrich, P. \& Schlagnhaufer, B. (1993) Transmission of La France isometric virus during basidiosporogenesis in Agaricus bisporus. Mycologia 85: 175-179.

Sambrook, J., Fritsch, E. F. \& Maniatis, T. (1989) Molecular Cloning: a laboratory manual. Cold Spring Harbor Laboratory Press, New York.

Schisler, L. C., Sinden, J. W. \& Sigel, E. M. (1963) Transmission of a virus disease of mushrooms by infected spores. Phytopathology 53: 888 .

Schisler, L. C., Sinden, J. W. \& Sigel, E. M. (1967) Etiology, symptomatology and epidemiology of a virus disease of cultivated mushrooms. Phytopathology 57: 519-526.

Tartaglia, J., Paul, C. P., Fulbright, D. W. \& Nuss, D. L. (1986) Structural properties of double-stranded RNAs associated with biological control of chestnut blight fungus. Proceedings of the National Academy of Science, USA 83: 9109-9113.

van Griensven, L. J. L. D. (1988) The Cultivation of Mushrooms. Darlington Mushroom Laboratories, Rustington. van der Lende, T. R., Harmsen, M. C. \& Wessels, J. G. H. (1994) Double-stranded RNAs and proteins associated with the $34 \mathrm{~nm}$ virus particles of the cultivated mushroom Agaricus bisporus. Journal of General Virology 75: 2533-2536.

van Miltenburg, R., Rügger, B., Grünewald-Janho, S. \& Schröder, C. (1995) RNA/Northern blotting and hybridization required solutions and buffers. In The DIG System User's Guide for Filter Hybridization (R. van Miltenburg, B. Rügger, S. Grünewald-Janho \& C. Schröder, eds): 84. Roche Molecular Biochemicals, Mannheim.

van Zaayen, A. (1979) Mushroom viruses. In Viruses and Plasmids in Fungi (P. A. Lemke, ed.): 239-324. Marcel Dekker, New York.

Wach, M. P. A., Sriskantha, A. \& Romaine, C. P. (1987) Doublestranded RNAs associated with La France disease of the commercial mushroom. Phytopathology 77: 1321-1325.

Corresponding Editor: J. I. Lelley 